\title{
The biology of the endophyte/grass partnership
}

\author{
M.J CHRISTENSEN and C.R. VOISEY. \\ AgResearch Grasslands, Private Bag 11008, Palmerston North, New Zealand \\ mike.christensen@agresearch.co.nz
}

\begin{abstract}
The association of Epichloë and Neotyphodium endophytes with host grasses is one of balance between both partners. The host plants are symptomless with the exception of stromata that can form on reproductive tillers of grasses infected with Epichloë spp. The hyphae of the endophytes, spread systemically throughout the above ground parts of plants and in leaves, are aligned parallel with the longitudinal leaf axis and are seldom branched. In this review, the reader is guided through the interaction of host grass and endophytes as revealed by microscopy and then given a model to explain the unique association that these endophytic fungi have with host grasses. This model proposes that hyphae within meristematic tissue branch profusely, providing hyphal strands that extend by intercalary growth amongst enlarging plant cells. Hyphae cease branching and elongating when amongst stationary cells but remain metabolically active, producing a range of bioactive products that enhance the persistence of host grasses. By this process the synchronisation of endophyte and plant growth is achieved, providing a generally mutualistic relationship.
\end{abstract}

Keywords: Neotyphodium, Epichloë, intercalary hyphal extension

\section{Introduction}

In writing this paper on the biology of the endophyte-grass symbiosis our aim is to take the reader on a journey of discovery on how the endophyte grows within the plant giving rise to what we like to refer to as a 'perfect partnership'. This journey involves microscopy by which we can observe the endophyte in the different components of the plant and by doing so come up with some hypotheses to explain the growth, hypotheses which can and have been tested. If we are successful, the way that the endophyte grows in the host grass will be easy to understand and the knowledge will provide the basis for research to better utilise the properties of these fungi to enhance forage production.

\section{The Unique Endophyte Lifestyle - What is Revealed Using Microscopy}

When we look at a transverse cross section of typical endophyteinfected grass leaves (Figs. 1\&2), several key factors about the habitat that the endophyte occupies, and its association with the host grass, are clearly visible. The hyphae of the endophyte are between the plant cells. They nearly all appear as if they are small dense cells when in fact they are long filaments, a consequence of the hyphae being orientated parallel to the longitudinal leaf axis (Fig. 3). The hyphae are in close contact with the cells and appear to be firmly attached (Figs. $1 \& 2,4 \& 5$ ). In leaf sheaths, except for those that are young, many hyphae are attached to the walls of degenerated mesophyll cells (Fig. 6). In contrast to this, the hyphae in blades remain attached to living cells during the life of the leaf. The plant cells typically appear completely unaffected by the attachment of the hyphae. The hyphae comprise a small portion of the leaf profile, but their content is dense and lacking vacuoles, in contrast to most plant cells which contain large vacuoles. Typically, very few hyphae are present within the vascular bundles. No other microorganisms can be seen in this food-containing stable habitat that the leaf provides.

The exception to this description of hyphae of Epichloë and Neotyphodium endophytes in leaves of their grass host is seen with annual ryegrasses infected with $N$. occultans, the hidden endophyte. This endophyte is present in leaves as a tangled mass in the basal few mm where the hyphae can easily remain undetected unless the very basal leaf tissue is included when microscopic examination is undertaken (Figs. 7-9).

Located at the base of expanding leaves of plants infected with all Epichloë and Neotyphodium endophytes is a network of branching hyphae (Fig. 10). This network of hyphae is located below the leaf expansion zone and originating from here are the long, seldom-branched hyphae growing between the columns of leaf cells. Hyphal branches sometimes link two hyphae separated by a column of cells (Fig. 11). Hyphae are present in the ligular zone which separates the blade and the sheath (Fig. 12), with some hyphae continuous through this zone, being partly in the sheath and partly in the blade. Hyphae are present in the meristematic tissue at the apex of tillers (Fig. 13) although the number present at the most apical portion is low, as is the presence of branches. However, as the distance below the apex increases, the number of hyphae increases and they ramify throughout the undifferentiated plant tissue (Figs. 14 \&15).

Examination of elongating leaves reveals that, at all distances above the leaf base, hyphae are dense and lacking vacuoles. In the basal few $\mathrm{cm}$ of elongating leaves, the cytoplasm of all hyphae is similar and simple, consisting largely of ribosomes, mitochondria and nuclei (Fig. 16). Higher up the leaf, above the leaf expansion zone, the cytoplasm of all hyphae is again similar and is more complex than in the lower, younger leaf tissue. This increased complexity includes lipid droplets and with some species, protein crystals and tubule bodies (Fig. 17). At all distances above the leaf base the lengths of hyphal compartments are similar.

The number of hyphae of Neotyphodium and Epichloë endophytes does not increase as leaves age. This can be clearly seen in old leaves infected by both $N$. lolii and an unrelated fungal endophyte (a "p-endophyte") for which the number of hyphae becomes very high in old leaves and orientated in all directions (Fig. 18). The similarities in the number of Epichloë and Neotyphodium hyphae present in young and old leaves is even more apparent in thin transverse sections of endophyte-infected grass tillers where adjacent leaves of different ages are present. It can also be noted that hyphae are essentially evenly distributed in leaf sheaths (Fig. 19). Two other features of Neotyphodium and Epichloë endophytes, evident from examining cross sections of tillers, are that the diameter of hyphae increases as the age of the leaf increases (Fig. 19) and that hyphae tend to be located in clusters in leaf blades (Fig. 20).

In some associations, particularly those involving Epichloëspp., hyphae can be both within and outside the leaf (Figs. 21\&25). The epiphytic hyphae emerge from between epidermal cells in the lower part of the leaf expansion zone and remain connected to the endophytic hyphae within the leaf. These external hyphae can form branches and even produce conidia. They are not visible to the naked eye.

If we examine by fluorescence microscopy dead leaf sheaths of grasses infected with an endophyte that has been genetically 
modified to produce a green fluorescent protein (GFP), we can distinguish hyphae of the endophyte by their green glow even though many other fungi may have begun to colonise the decaying tissue. By this microscopy technique we can observe that the hyphae remain as they were when the leaf was alive and have not started to grow as a saprotroph (Fig. 26).

Vegetative tillers are composed of leaves, the sheaths and immature emerging leaves forming the pseudostem. The oldest leaf is the outermost (Fig. 27). Located at the base is the true stem (Fig. 28), where hyphae are scattered throughout but not densely concentrated (Fig. 29) even though this is the oldest part of each tiller. From the use of GFP-expressing endophytes we can observe that these hyphae are dense and active as the hyphae glow bright green when exposed to the appropriate light frequency. Confirmation of this has come from examination using transmission electron microscopy (TEM). From the use of GFP-expressing endophytes we can also observe that hyphae are often present in the tips of roots that commence development from within the true stem (Fig. 30).

Further information about the way the endophyte interacts with the host grass comes from the examination of immature inflorescences as they commence their development from meristematic tissue at the base of tillers (Figs. 31\&32). Hyphae keep pace with the immature inflorescences from the time they start developing. Hyphae can be observed in the developing floral parts where they are in immature ovaries and often in anthers (but not in the pollen) (Figs. 33-36). The embryo, including the scutellum, and the nucellus layer of the seed, are colonised by the time the seed is mature (Figs. 37\&38).

\section{Growth of the Endophyte and Host is Synchronised}

The key point that has emerged from our microscopy observations is that the growth of the endophyte is synchronised with that of the host. The most obvious evidence for this is that leaves are colonised only while they are elongating and thus the number of hyphae does not increase as the leaves age. Hyphal growth keeps pace with that of the elongating leaf as if the hyphal strands are being towed up the leaf. Once in place within mature leaf tissue the hyphae cease extending and do not form branches but stay metabolically active as shown by the accumulation of lipid droplets through ongoing absorption of nutrients. This ongoing formation of lipid droplets and other substances results in hyphae becoming wider as they age.

The synchronisation of the growth of the endophytes is not just with the growth of leaves but with all stages of the growth of host grasses. Each axillary bud from which tillers develop is typically colonised as it forms on the meristematic zone situated at the base of the tillers. This meristematic zone is henceforth referred to as the shoot apical meristem (SAM). Inflorescences too are colonised as they start to develop on the top of the SAM. All floral parts and each seed, importantly including the embryo, can be colonised as they commence their development. When seeds germinate the endophyte becomes active and keeps pace with the growth of the seedling. Adventitious roots can also become infected as they start their development in the true stem below the meristematic zone from which the above ground plant parts originate.

\section{"P-endophytes", contrasting endophytes without synchronised growth}

The synchronised growth of Epichloë and Neotyphodium endophytes can be best appreciated by a comparison with the unrelated "p-endophytes". These endophytes, found in some Lolium and Festuca species, are not closely related to the Epichloë and Neotyphodium species, and were originally described as Gliocladium-like and Phialophora-like endophytes depending on their host grass (Latch et al. 1984). All are now collectively referred to as the "p-endophytes"; endophytes with penicilliate conidiophores (An et al. 1993). The interaction of these endophytes with host grasses contrasts markedly with that of the Epichloë and Neotyphodium endophytes in that their growth is not synchronised with that of host grasses. Through ongoing growth the number of hyphae present greatly increases as leaves age. Instead of the hyphae being orientated parallel to the longitudinal leaf axis and being even in diameter with few lateral branches, those of p-endophytes are orientated in all directions, highly branched and are variable in diameter. Large numbers of conidia are produced within senescent leaves in autumn (Philipson 1989, 1991a, b). The abundant hyphae of p-endophytes become packed with lipid droplets, a further indication that they are obtaining and using many plant-produced nutrients, although surprisingly this has little effect on host growth with infected plants being symptomless (Latch et al. 1985).

\section{A Model for Growth of Endophytes in Host Grasses}

Based on the findings from microscopy examination we propose the following model to explain the growth of Epichloë and Neotyphodium endophytes in host grasses. Hyphae enter meristematic zones where the number of hyphae rapidly increases by profuse branching. If plant cells produced by meristems enlarge rapidly, as happens in the leaf expansion zone and in the internodal region of the flowering stem, the portions of hyphal strands within these tissues elongate at the same rate at which the cells are enlarging. This elongation occurring away from the tip is known as intercalary extension and may be unique to these and perhaps other clavicipitaceous endophytic fungi. When hyphae are no longer amongst dividing or enlarging cells they cease elongating and dividing but remain highly metabolically active. It is through these three distinct states of hyphal growth and regulation that the growth of the endophyte is synchronised fully with that of the host grass.

\section{Evidence supporting the model for endophyte growth in host plants}

Research carried out largely at AgResearch has provided considerable evidence in support of this model of growth. Profusely branching hyphae can be observed microscopically within zones of dividing plant cells, especially using the GFPexpressing endophyte strains. A clear example of this is in the developing leaf where a dense network of branching hyphae is formed amongst the meristematic tissue at the leaf base. Rapid formation of hyphal branches is essential if tissues are to become colonised solely while they are developing.

Our GFP-expressing endophyte strains have enabled us to directly measure intercalary extension of hyphae in the leaf expansion zone by time lapse photography. In addition we have measured the length of hyphal compartments at various distances above the base of developing leaves. We have also carried out detailed examination of hyphae in expanding leaves using TEM, noting hyphal ultrastructure and the way that hyphae interact with neighbouring cells. Further we have noted the concentration of the endophyte-produced alkaloid lolitrem B in young (basal) and old (upper) expanding leaf tissue. All of these procedures have provided further understanding of the process of intercalary extension that enables the hyphae to grow at exactly the same speed as expanding leaves. These observations also indicate a probable mechanism that drives intercalary extension. 
Figure 1 Light micrograph of a perennial ryegrass leaf blade showing hyphae $(\leftarrow)$ attached to leaf cells, notably those cells adjacent to the vascular bundle.

Figure 2 Electron micrograph showing five hyphae within intercellular spaces of perennial ryegrass leaf sheath mesophyll. Note that all hyphae are dense and are flattened where in contact with host cells.

Figure $3 N$. lolii $(\leftarrow)$ hyphae in epidermal strip from sheath of mature perennial ryegrass leaf. Note that the hyphae are unbranched and run parallel with the long epidermal cells.

Figure 4 Electron micrograph showing two hyphae attached to mesophyll cells within a perennial ryegrass leaf blade. Note that the hyphae are dense and not round.

Figure $5 \mathrm{~N}$. lolii hyphae between two leaf blade mesophyll cells. Note the elongate appearance of the hypha as though it is being stretched and the flattened wall where it is in contact with the two cells.

Figure 6 Light micrograph of mature ryegrass leaf sheath showing dense $N$. Iolii hyphae attached to the walls of degenerate mesophyll cells.
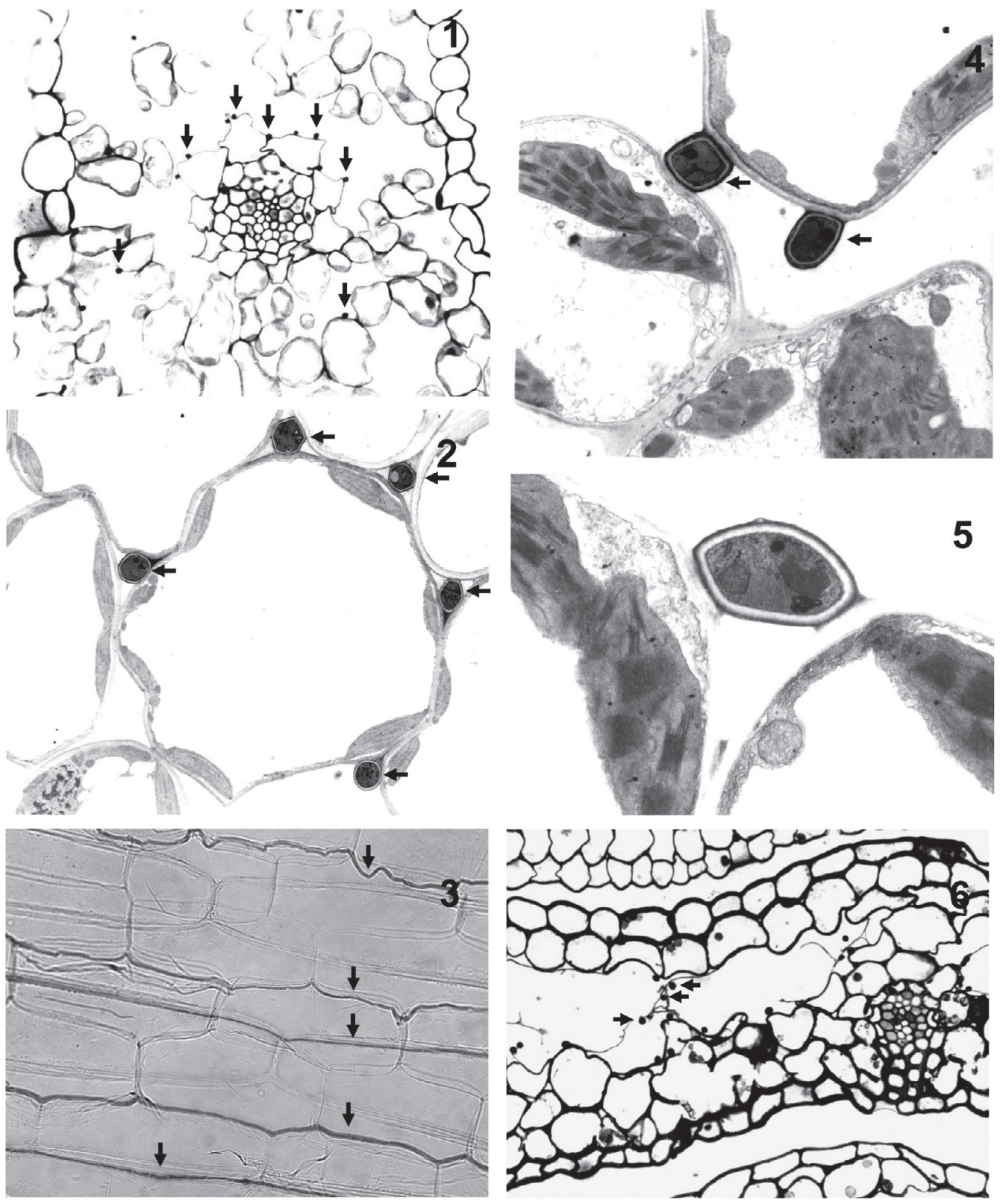
Figure 7-9 Light micrographs showing $N$. occultans hyphae in the basal few $\mathrm{mm}$ of hybrid annual ryegrass leaf.

Figure 7 Basal few mm of intact leaf showing that the majority of hyphae $(H)$ are present as a tangled mass.

Figure 8 Longitudinal section of leaf base showing the dense aggregate of hyphae .

Figure 9 Transverse section close to leaf base showing intercellular spaces containing many hyphae $(\leftarrow)$. Note that the hyphae are confined to the outer portion of the leaf tissue.

Figure 10 Light micrograph showing network of hyphae $(\leftarrow)$ in the base of an expanding ryegrass leaf and elongate hyphae that originate from the branching hyphae.

Figure 11 Fluorescence micrograph showing branched longitudinal hyphae of a GFP-expressing E. festucae strain in the leaf expansion zone. Note the presence of many branches, some of which link adjacent hyphae.

Figure 12 Fluorescence micrograph showing hypha of a GFP-expressing N. lolii strain in the ligular zone of an expanding perennial ryegrass leaf. Note that some hyphae are continuous through the zone $(\mathrm{L})$ that separates blade (B) and sheath (S).
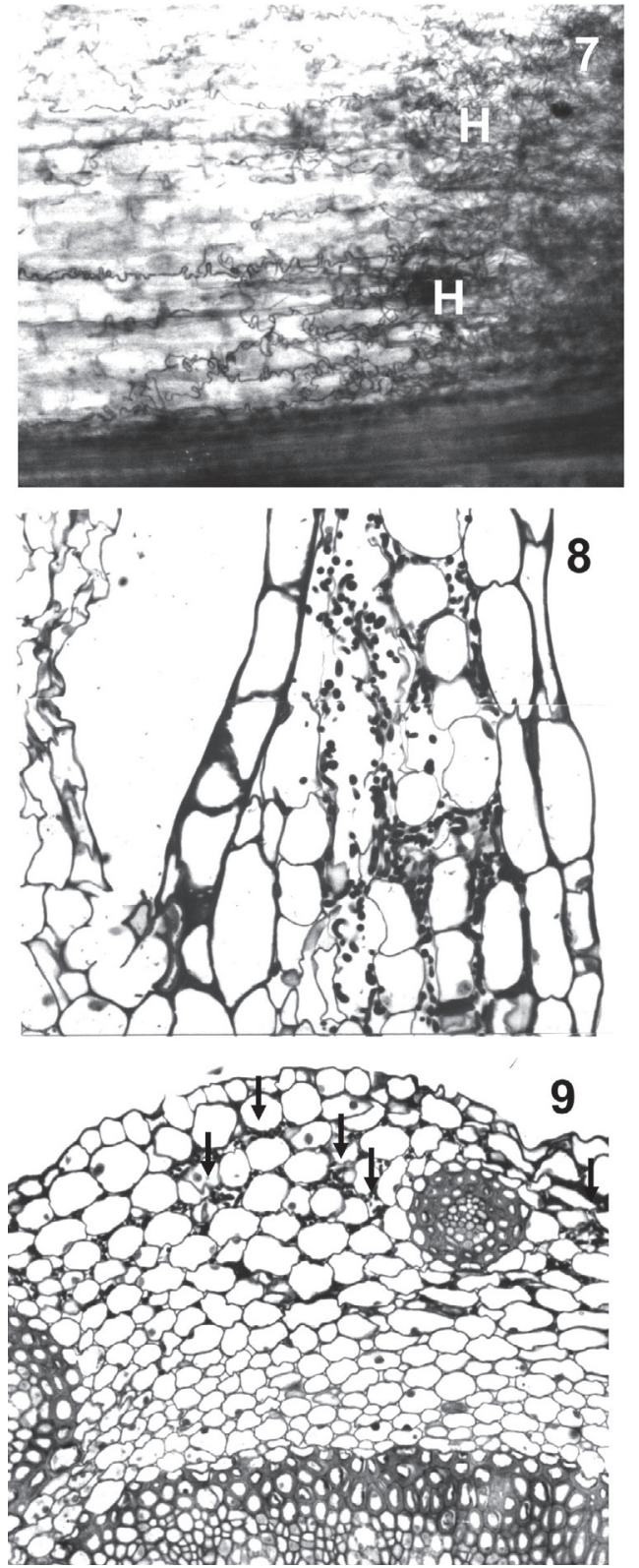
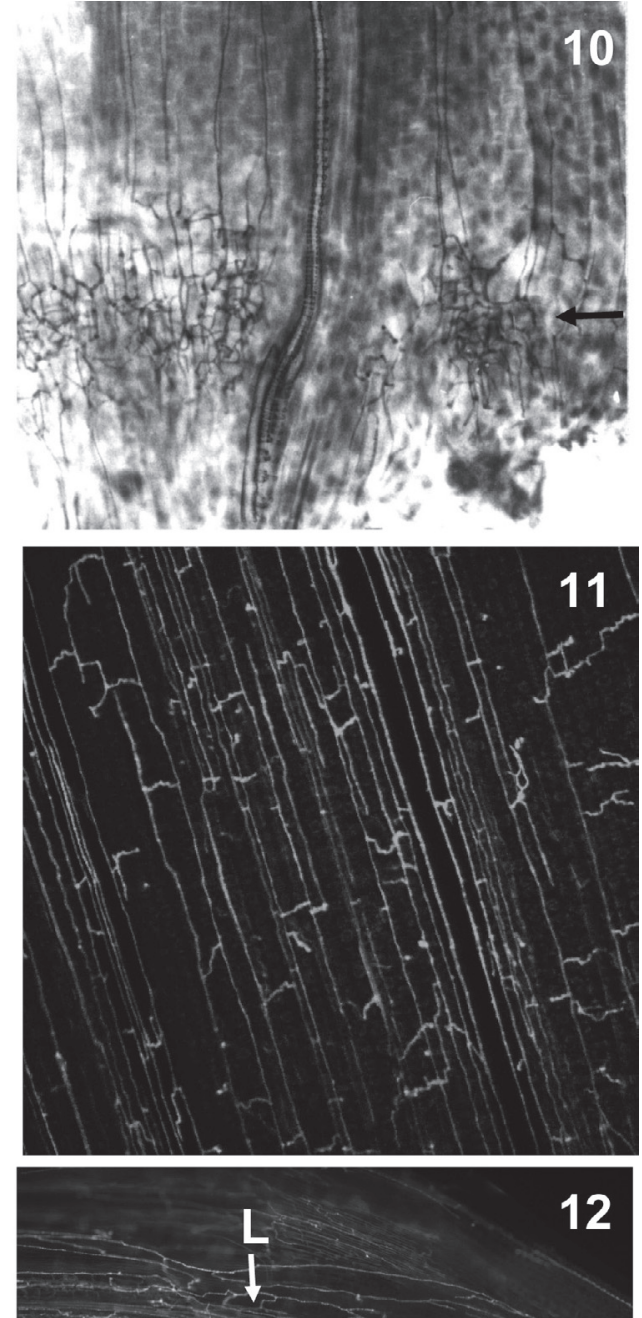

B

S 
Figure 13 Light micrograph of $N$. coenophialum hyphae $(\leftarrow)$ in the meristematic zone at the apex of a vegetative tiller of a Mediterranean-type tall fescue.

Figure 14 Light micrograph showing a transverse section close to the apex of a tiller of a Mediterranean tall fescue.

Figure 15 Electron micrograph showing numerous $N$. coenophialum hyphae which are orientated in all directions in the intercellular spaces of the undifferentiated tissue in the region indicated in Fig. 14.

Figure 16 Electron micrograph showing a representative $N$. lolii hypha $(\mathrm{H})$ in the lower expansion zone of an elongating perennial ryegrass leaf. $M=$ mitochondrion.

Figure 17 Electron micrograph showing a representative $N$. lolii hypha in a mature leaf blade. $\mathrm{C}=$ protein crystal, $\mathrm{T}=$ tubule body.

Figure 18 Light micrograph showing a N. Iolii hypha $\leftrightarrow$ ) along with numerous hyphae of a "p-endophyte" in an old perennial ryegrass leaf sheath. Note the even diameter of the $N$. lolii hypha and the numerous hyphae of the ' $p-$ endophyte are irregular in diameter and are orientated in all directions.
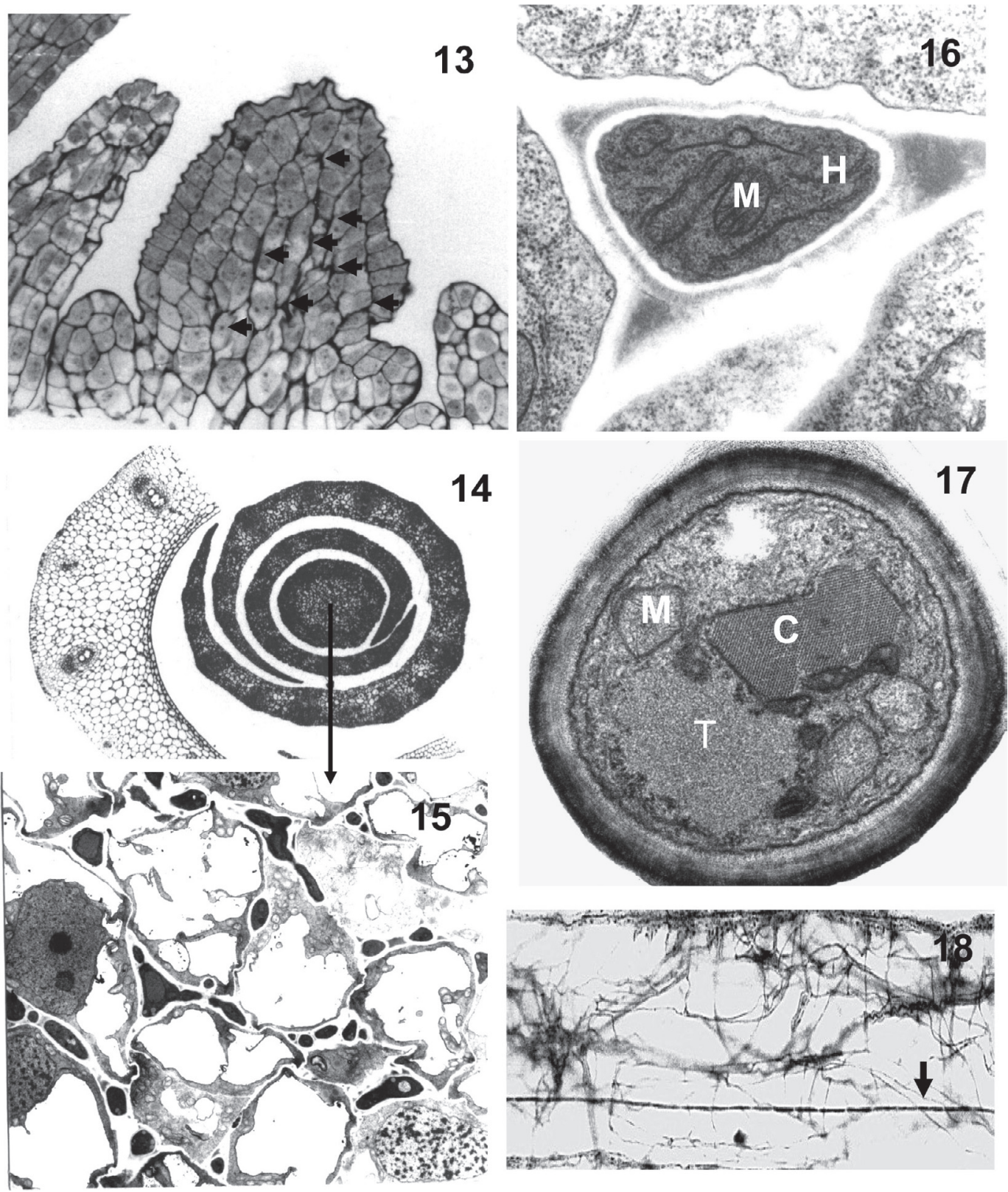
Figure 19 Light micrograph of transversely sectioned young and old sheaths of a perennial ryegrass plant infected with E. typhina. Note that the hyphae are evenly distributed and that those in the older outer sheath $(\leftarrow)$ are conspicuously larger than those in the younger sheath.

Figure 20 Light micrograph showing a transverse section through the expansion zone of an elongating leaf blade. Note that the hyphae $(\leftarrow)$ are not evenly distributed within the elongating leaf blade.

Figure 21 Light micrograph showing hyphae $(\leftarrow)$ of a symptomless Epichloë sp. outside of the leaves of a Poa sp.

Figure 22 Light micrograph of a transverse section through the lower expansion zone of a perennial ryegrass leaf. An E. festucae hypha that has penetrated between epidermal cells is indicated.

Figure 23 Light micrograph showing two short E. festucae hyphae $(\leftarrow)$ that have grown out through the epidermis in the lower expansion zone of a leaf blade to become situated on the leaf surface.

Figure 24 Light micrograph showing E. festucae branching hyphae on the surface of the lower part of an expanding perennial ryegrass leaf.

Figure 25 Light micrograph showing conidia-producing phialides $(\leftarrow)$ of $E$. typhina on the surface of a perennial ryegrass leaf.

Figure 26 Fluorescence microscopy photo showing GFP-expressing E. festucae hyphae in a dead outer leaf sheath of a perennial ryegrass tiller.
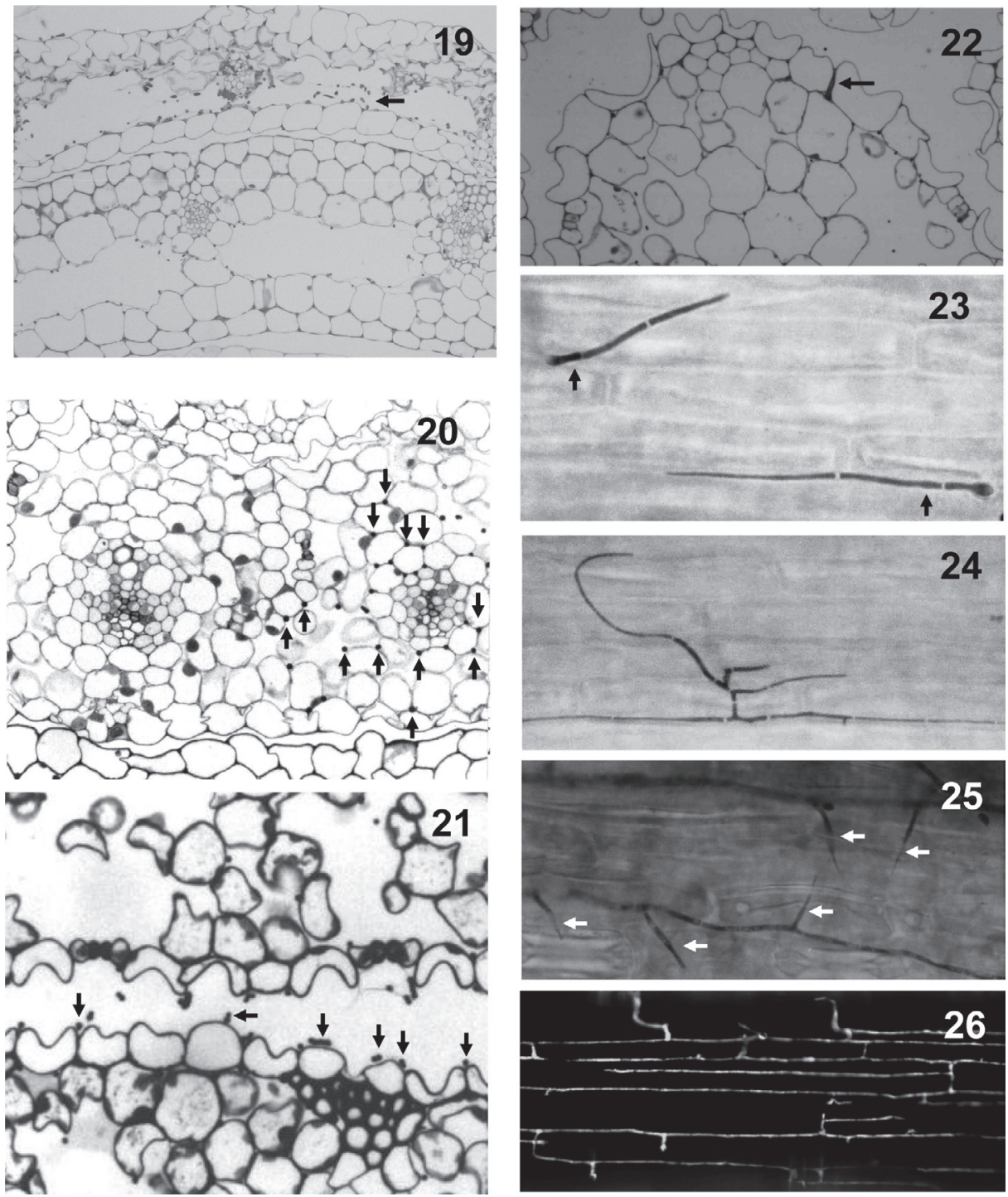
Figure 27 Fluorescence microscopy photo of a transverse section of the pseudostem of a perennial ryegrass tiller. Hyphae are the green dots resulting from the presence of GFP and note that they are much larger in the outer than inner leaf sheath (S). The red pigment that is so strong in the emerging leaf blade (B) and the daughter tiller (DT) is from auto-fluorescence of chloroplasts.

Figure 28 Fluorescence microscopy photo at the base of a perennial ryegrass tiller showing the true stem (S) that is surrounded by the lower parts of four leaves. The innermost leaf is attached to the part of the stem shown in this micrograph. The green is from fluorescence of the hyphae with GFP and the yellow is the auto fluorescence of vascular bundles.

Figure 29 Fluorescence microscopy photo showing GFP-expressing hyphae in the central region of the perennial ryegrass stem. Note that some hyphae are ramifying through the outer stem tissue.

Figure 30 Fluorescence microscopy photo showing GFP expressing $E$. festucae hyphae in the tip of a perennial ryegrass root.

Figure 31-32 An immature ryegrass inflorescence infected with a GFP-expressing E. festucae strain. Note that some hyphae are present along the entire visible length and a few are present in each lobe.
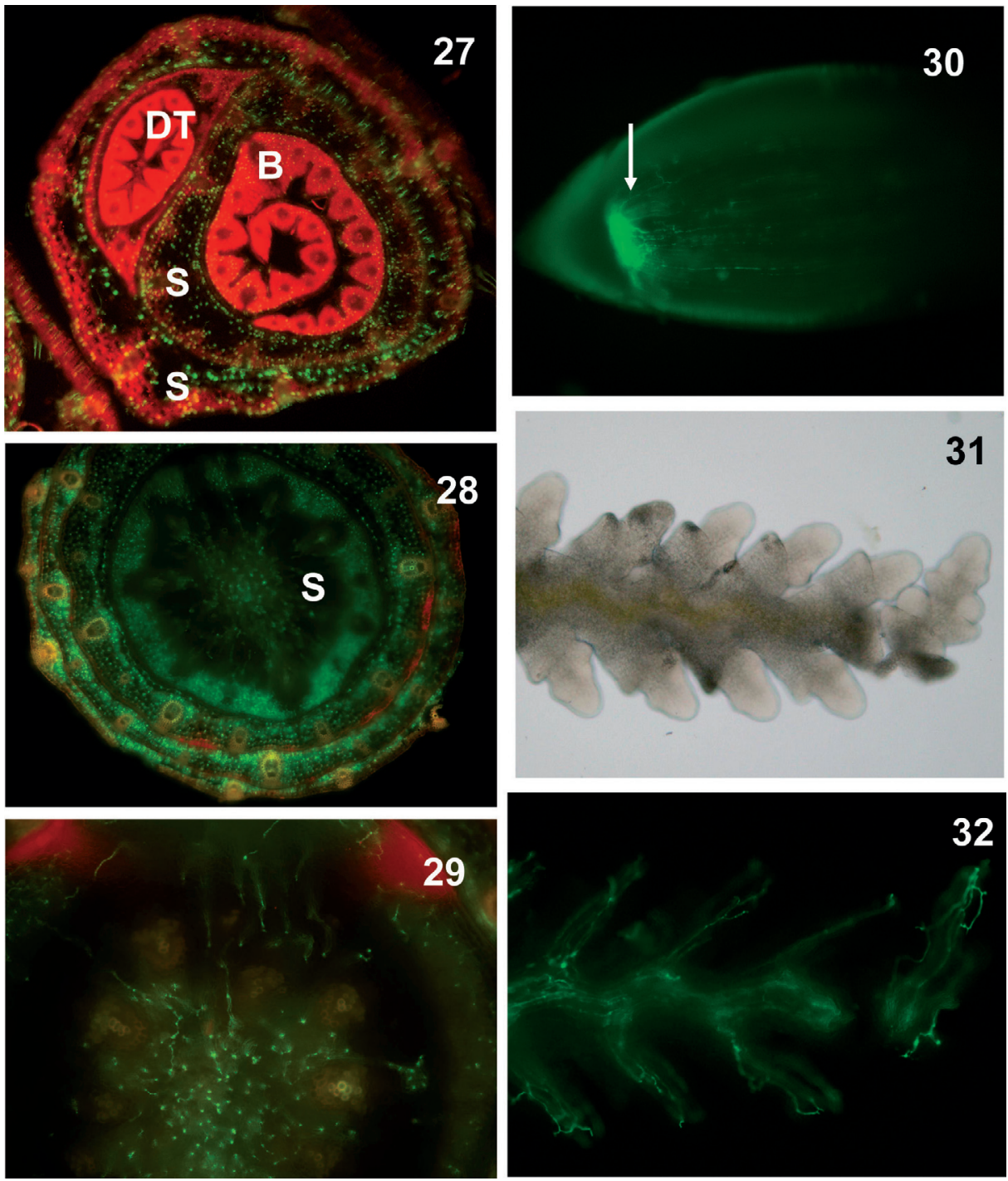
Figure 33-38 Floral and seed structures from perennial ryegrass plants infected with a GFP-expressing E. festucae strain.

Figure 33 Anther with a network of hyphae.

Figure 34 Two anthers, one of which has some hyphae. Note that no hyphae appear in pollen grains $(\leftarrow)$.

Figure 35 Immature ovary that is extensively colonised by hyphae, including the stigmata.

Figure 36 Hyphae colonising an ovary.

Figure 37 Cross section through the embryo-containing part of a seed. Note that hyphae are present in the embryonic axis (E) and are abundant in the portion of the scutellum (S) close to the endosperm.

Some hyphae are also present in the nucellus layer close to the seed coat.

Figure 38 Hyphae are present throughout the embryonic axis.
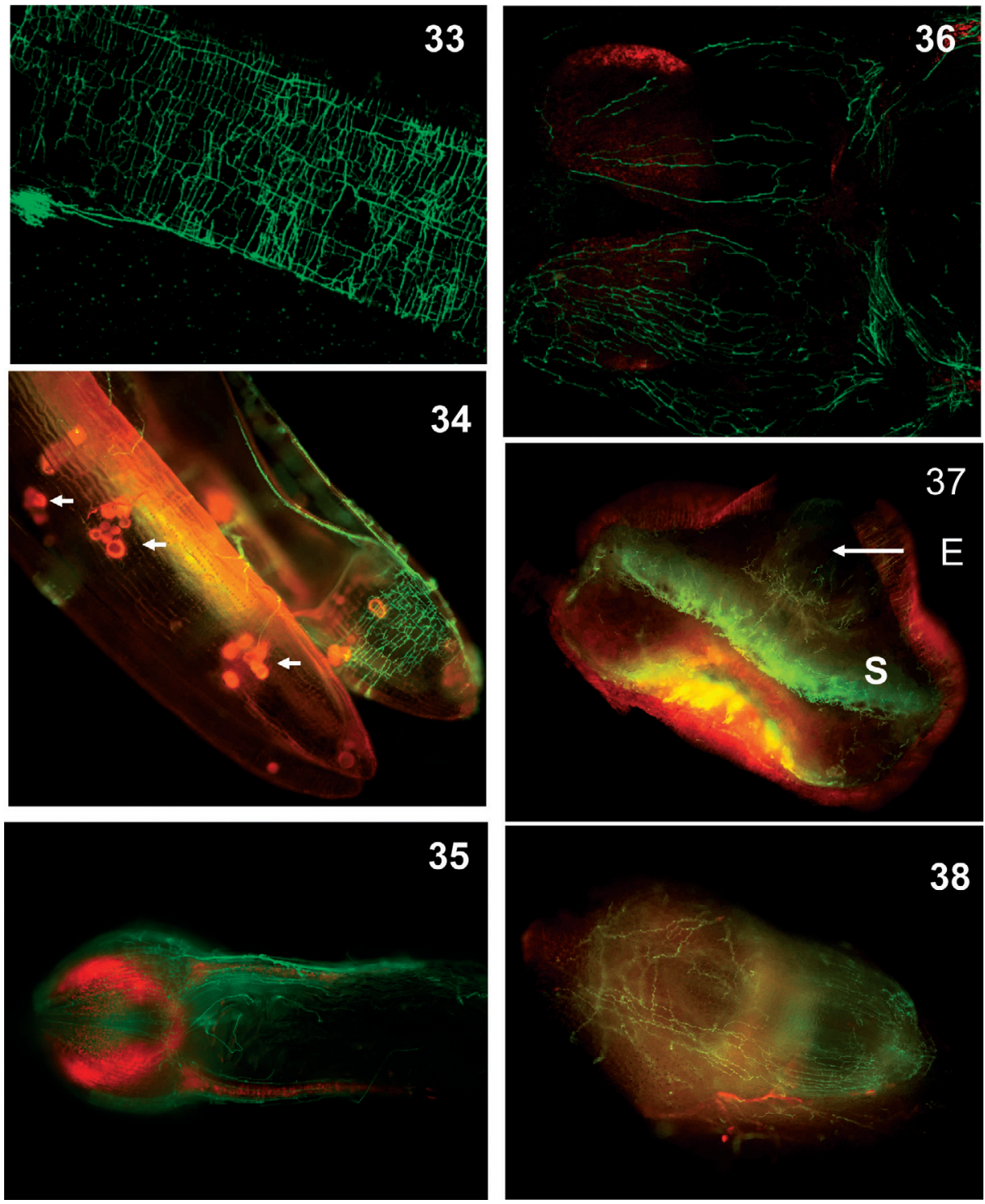
The third phase of the endophyte growth model, that of the retention of a high metabolic rate in hyphae after they have ceased elongating and branching, has been experimentally shown (Tan et al. 2001). The retention of dense cytoplasm, the increase in diameter, the accumulation of lipid droplets and sometimes protein crystals and tubule bodies (Christensen et al. 2002), and the greater intensity of GFP as hyphae age are all visual evidence that hyphae are metabolically active following cessation of hyphal extension.

\section{The mechanism for intercalary extension}

The process of intercalary extension is probably driven by longitudinal stretching being applied to hyphae by their attachment to enlarging plant cells. This attachment to host cells has been revealed in studies of elongating leaves involving light, transmission and scanning electron microscopy. Through this process each segment of a hypha within the expansion zone reacts to the elongation of the cells to which it is attached and increases in length. Each part of the hyphal strand can evidently carry out the growth processes that happen only at the hyphal tips of other fungi. Through this process all Epichloë and Neotyphodium strains will grow at exactly the same rate; that of the elongating tissue. When the cells to which hyphae are attached cease enlarging, such as when hyphae are conveyored out of the leaf expansion zone, the hyphae are no longer subjected to stretching and intercalary extension generally ceases.

\section{Epiphyllous hyphae result from tip growth of branches in the lower expansion zone}

With some associations of Epichloë and to a much lesser extent Neotyphodium strains, hyphae are present on the outside of leaves (Moy et al., 2000). As stated earlier these hyphae emerge from the leaf by penetrating between the epidermal cells of the lower expansion zone. With these strains, considerable branching occurs in the lower expansion zone where some division of mesophyll cells is still occurring. Epiphytic hyphae remain connected to the endophytic hyphae from which they arise as the leaf elongates but like those hyphae they also stop growing and so never become visible to the naked eye. The presence of epiphytic hyphae is not just a feature of the endophyte strain but is influenced by the host genotype. Epiphytic hyphae are generally absent on perennial ryegrass plants infected with $N$. lolii but with strain AR1 they were present in an artificially infected ryegrass with strong Lolium multiflorum characteristics (Christensen et al. 2001).

\section{The formation of endophyte-free tillers can be explained by} the model of growth

Axillary buds, like leaves, become infected from hyphae growing within the basal mass of dividing cells of the SAM zone. A likely reason for the formation of endophyte-free tillers is the limited time that axillary buds are connected to the meristematic zone and can be colonised.. If hyphae do not enter an axillary bud while it is still part of this meristematic zone it will become isolated by a layer of non-dividing cells and so forever remain endophyte-free.

\section{Roots are poorly colonised by Epichloë and Neotyphodium endophytes}

Hyphae of endophytes expressing GFP have been observed in the tips of adventitious roots. No hyphae can be observed along the root or in the tip of branch roots. This infection can be traced back to the time when roots are being formed in a point meristem within the true stem. Hyphae are also present in the radical (first root) of the mature embryo. Hyphae are retained in the tip region but are not among the cells laid down behind the meristem as it advances.

\section{Stroma development}

A feature that distinguishes Epichloë from Neotyphodium endophytes is that all Epichloë spp. have the potential to produce stromata, dense masses of fungal growth in which the sexual stage is formed (Schardl \& Phillips 1997). Stroma production has only been reported in reproductive tillers, with the mass of conspicuous internal and external hyphal growth confined to above the top visible node preventing the emergence of the inflorescence (choke disease). Recently, stroma-like growth has been observed on leaf blades of vegetative tillers of perennial ryegrass plants infected with E. typhina (Christensen et al. paper prepared).

Stroma formation occurs when the hyphal growth ceases to be synchronised with the host and becomes ongoing, resulting in profuse branching and thus large numbers of tip extending hyphae. Loss of synchronisation of E. typhina hyphae and also hyphae of some other Epichloë spp. leading to stromata occurs in nearly all reproductive tillers in nearly all host species. With other Epichloë species only a few reproductive tillers may have stromata (White 1988). ). In contrast to the reproductive tillers, stroma formation on leaf blades of vegetative tillers of perennial ryegrass plants infected with E. typhina happens very infrequently, resembling the occasional production of stromata by Epichloë spp. that have both vertical and horizontal dissemination. Conspicuous epiphytic along with profuse endophytic growth has been observed on the inflorescences of some perennial ryegrasses infected with a particular Neotyphodium strain (Christensen \& Saulsbury 2007). This is a rare occurrence and was only observed in a very small percentage of the ryegrass population.

\section{What sets the hyphal regulation of endophytes in grasses, the plant or the endophyte?}

The regulation of hyphal growth of Epichloë and Neotyphodium endophytes in the host plant is different from that which occurs when these fungi are growing in culture where growth is ongoing. A key question is whether it is the plant that is regulating the hyphal growth or if the fungus has a mechanism that provides this synchronisation?

The extent to which leaves, including the blades, are colonised, the biomass of hyphae and the concentration and ratio of alkaloids (Christensen et al. 1997; Christensen et al. 1998; Easton et al. 2002; Faville et al. 2007; Spiering et al. 2005) are all strongly influenced by host genotype. The frequency of hyphae being present within vascular bundles is another example of the host genotype effect on the endophyte. In natural associations of Neotyphodium endophytes with grasses, vascular bundles contain few hyphae. However, with $N$. lolii strain AR1, extensively colonised vascular bundles were present in some artificiallyinfected ryegrasses with strong $L$. multiflorum characteristics (Christensen et al. 2001).

A hypothesis to explain synchronisation of hyphal growth with that of the host is that the host grass provides a regulating signal. Ongoing hyphal growth such as that required to produce Epichloë stromata and develop stroma-like growth of a Neotyphodium strain on some perennial ryegrass inflorescences, may result from plant signals being too weak to maintain synchronised hyphal growth.

The endophyte also plays a major role in maintaining the 
synchronisation of hyphal and plant growth. This has been clearly demonstrated by the disruption of reactive oxygen species (ROS) production of an E. festucae strain which resulted in ongoing hyphal growth in perennial ryegrass plants, excessive colonisation of meristematic tissue, and stunting and premature senescence of leaves (Tanaka et al. 2006; Takemoto et al. 2006). However, at least some of the effects on hyphal regulation resulting from the disruption of ROS production were dependant on the host plant in which the strains were growing (Tanaka et al. 2007). Thus the control of endophyte growth and secondary metabolism appears to be a combination of both plant and endophyte factors.

\section{The Symbiosis is a Delicate Balance}

The apparently mutualistic association between Epichloë and Neotyphodium endophytes and host grasses is delicately balanced. This delicate balance can be dramatically upset. Seedlings inoculated with some endophytes can become stunted (Christensen et al. 1997). Stunting as well as the loss of synchronisation of hyphal growth with that of the host grass can result from changes to the endophyte (Tanaka et al. 2006; Takemoto et al. 2006).

Changes in the ambient temperature can alter the nature of the interaction between endophytes and their host grasses. Two studies in New Zealand of field populations of perennial ryegrass infected with $N$. lolii have found that the number of hyphae present in leaves was lowest in the winter months. In one study in a warm northern region, monthly visual assessments showed that the number of hyphae present in winter was about $25 \%$ of that in the summer (di Menna \& Waller 1986). The other study in the south with colder winter temperatures, found that hyphae were only occasionally seen in leaves in winter but became more common by mid-spring with most being present in the youngest leaf sheath (Philipson 1989). These findings may indicate that in cool temperatures the hyphae colonise the basal meristematic zones of expanding leaves more slowly and so fewer hyphae are present to extend into leaves. If so, colonisation is still fast enough to ensure that nearly all daughter tillers are infected. Another possible effect of cool temperatures is that the hyphae colonise the basal meristematic zone of leaves but are unable to elongate fast enough by intercalary growth to become distributed throughout leaves.

Changes to Epichloë and Neotyphodium endophytes resulting in a disturbance to the delicately balanced relationship with the host grass can occur spontaneously in the plant. This has been dramatically shown in two examples reported by Simpson et al. (2007). In the first example a spontaneous change to a $N$. lolii endophyte resulted in subsequent host perennial ryegrass plants being conspicuously small. In the second example a spontaneous change to an E. festucae strain turned a symtomless mutualist into a strain that not only caused plants to be stunted but which also had ongoing endophytic hyphal growth. Ryegrasses infected with this E. festucae strain are weak and most die after a few weeks of growth, even in the low-stress glasshouse environment.

What these observations illustrate is the constant selection pressure for fitness that is imposed on endophyte grass associations. Any change to the endophyte that 1) adversely affects the ability of the endophyte to grow synchronously with the host grass without turning on deleterious plant defense reactions; 2) adversely affects the growth of its host grass, or 3), causes the loss of a secondary metabolic pathway essential in enabling the association to persist better in the local ecosystem than endophyte-free grasses, will be selected against. This process is constantly at work, be it with the vegetative plant or following seed germination and seedling establishment. Only those seedlings that are competitive in the prevailing ecosystem and environmental conditions will establish and eventually produce seed to maintain the survival of the resident endophyte.

\section{Questions Requiring Answers}

The model of growth is a framework which provides an explanation for the colonisation of grasses by Epichloe and Neotyphodium endophytes but which leaves many questions unanswered. For instance why are leaf blades of some associations highly colonised whereas others have few if any hyphae (Christensen et al. 1997; Christensen et al. 1998)? An example of this is 'Kentucky 31 ' tall fescue infected with $N$. coenophialum, an extremely robust and successful mutualistic association. It is able to displace native plant species and thus in some ecosystems can be considered to be an invasive weed (Clay $\&$ Holah 1999). Leaf blades are poorly-colonised and yet hyphae are present along the entire sheath (Hinton \& Bacon 1985). Other continental-type tall fescue cultivars also have poorly colonised leaf blades. Poor colonisation of leaf blades may be a consequence of slower colonisation of meristematic tissue. The slow colonisation of meristems may also be the reason why endophyte-free tillers, a relatively low seed infection rate and poor retention of endophyte-viability of endophytes in seeds have been observed in some tall fescue-Neotyphodium associations (Welty \& Azevado 1993; Wilson \& Easton 1997). Thus it may be possible to select strains that are adapted for growth in either cold or hot climates and so give better colonisation of leaves, tillers and seeds.

The uniquely successful association between annual ryegrasses and $N$. occultans raises further questions. Is this an adaptation to the lifestyle of annual grass species that provides advantages from not having hyphae throughout leaves (possibly a lower energy cost to the host plant) while providing protection to the inflorescences, the seed and the developing seedling through the presence of endophyte-produced alkaloids? Is the failure of hyphae to colonise leaves due to the failure of hyphae to attach to cells in the leaf expansion zone with the consequence being that they are not "towed" upwards.

\section{Conclusion}

The association between Epichloë and Neotyphodium endophytes with their host grasses is the product of possibly unique adaptations of the fungal endophytes including the development of a signaling system by which hyphal growth is regulated. Through these adaptations the endophytes are able to synchronise their growth with that of host grasses, growing as if they were a host tissue with the function of carrying out protective chemistry that the host cannot do. With their growth occurring only while plant tissues are developing, the concentration of hyphae remains at a level that is not a significant cost to the plant, at least not in the forage pastoral ecosystems involving introduced species in New Zealand, Australia and the United States. Through a better understanding of the basic biology of the endophyte-grass symbiosis along with the application of technologies including DNA-based and analytic chemistry procedures our knowledge of the processes at work in this unique symbiosis between fungi and grasses will continue to unfold. Through this knowledge it may be possible to enlarge the benefits that endophytes provide to the forage agricultural industry and perhaps enable endophytes to find a role in additional grass species. 


\section{ACKNOWEDGEMENTS}

The authors wish to acknowledge that many people have played key supporting roles over many years which have enabled this understanding to be obtained. We wish to acknowledge the help of the members of the endophyte research team in the Forage Improvement and Forage Biotechnology sections of AgResearch. We also wish to acknowledge the help over many years from Raymond Bennett while at Hort Research with the preparation and sectioning of samples for detailed light microscopy and TEM studies. We also thank Nik Grbavac of Agriquality who shared his expertise with the seed side of the endophyte-plant biology.

\section{REFERENCES}

An, Z.-Q.; Siegel, M.R.; Hollin, W.; Tsai, H.-F.; Schmidt, D.; Schardl, C.L. 1993. Relationships among non - Acremonium sp. fungal endophytes in five grass species. Applied and Environmental Microbiology 59: 1540-1548.

Christensen, M.J.; Ball, O. J-P.; Bennett, R.J.; Schardl, C.L. 1997. Fungal and host genotype effects on compatibility and vascular colonisation by Epichloë festucae. Mycological Research 101: 493-501.

Christensen, M.J.; Easton, H.S.; Simpson, W.R.; Tapper, B.A 1998. Occurrence of the fungal endophyte Neotyphodium coenophialum in leaf blades of tall fescue and implications for stock health. New Zealand Journal of Agricultural Research 41: 595-602.

Christensen, M.J.; Bennett, R.J.; Schmid, J. 2001. Vascular bundle colonisation by Neotyphodium endophytes in natural and novel associations with grasses. Mycological Research 105:1239-1245

Christensen, M.J.; Bennett, R.J.; Schmid, J. 2002. Growth of Epichloë/Neotyphodium and p-endophytes in leaves of grass hosts. Mycological Research 106: 93-106.

Chistensen, M.J.; Salisbury, K. 2007. Conspicuous epiphytic growth of a Neotyphodium sp. endophyte on perennial ryegrass inflorescences. pp 155 In: Proceedings of the 6th International Symposium on Fungal Endophytes of Grasses, Eds. Popay, A.J.; Thom, E.R. Grassland Research \& Practice Series 13. New Zealand Grassland Association.

Clay, K.; Holah, J. 1999. Fungal endophyte symbiosis and plant diversity in successional fields. Science 285: 1742-1744.

di Menna, M.E.; Waller, J.E. 1986. Visual assessment of seasonal changes in amount of mycelium of Acremonium loliae in leaf sheaths of perennial ryegrass. New Zealand Journal of Agricultural Research 29: 111-116.

Easton, H.S.; Latch, G.C.M.; Tapper, B.A.; Ball, O.J.-P. 2002. Ryegrass host genetic control of concentrations of endophytederived alkaloids. Crop Science 42: 51-57.

Faville, M.J.; Koulman, A.; Briggs, L.; Cao, M.; Podmore, C.; Abraham, D. 2007. Exploring endophyte compatibility in perennial ryegrass. pp $143 \quad I n$ : Proceedings of the 6th International Symposium on Fungal Endophytes of Grasses, Eds. Popay, A.J.; Thom, E.R. Grassland Research \& Practice Series 13. New Zealand Grassland Association.

Hinton, D.M.; Bacon, C.W. 1985. The distribution and ultrastructure of the endophyte of toxic tall fescue. Canadian Journal of Botany 63: 36-42.

Latch, G.C.M.; Christensen, M.J.; Samuels, G.J. 1984. Five endophytes of Lolium and Festuca in New Zealand. Mycotaxon
20: $535-550$.

Latch, G.C.M; Hunt, W.F.; Musgrave, D.R. 1985. Endophytic fungi affect growth of perennial ryegrass. New Zealand Journal of Agricultural Research 28: 165-168.

Moy, M.; Belanger, F.; Duncan, R.; Freehoff, A.; Leary, C.; Meyer, W.; Sullivan, R.; White, J.F.Jr. 2000. Identification of epiphyllous mycelial nets on leaves of grasses infected by Clavicipitaceous endophytes. Symbiosis 28: 291-302

Philipson, M.N. 1989 A symptomless endophyte of rye-grass (Lolium perenne) that spores on its host - a light microscope study. New Zealand Journal of Botany 27: 513-519.

Philipson, M.N. 1991a. Ultrastructure of the Gliocladium-like endophyte of perennial ryegrass (Lolium perenne L.). 1. Vegetative phase and leaf blade sporulation. New Phytologist 117: 271-280.

Philipson, M.N. 1991b. Ultrastructure of a symptomless fungal endophyte of Festuca arundinacea. Botanical Gazette 152: 296-303.

Schardl, C.L.; Phillips, T.D. 1997. Protective grass endophytes. Where are they from and where are they going? Plant Disease 81: 430-438.

Simpson, W.R.; Christensen, M.J.; Johnson, R.D.; Schmid, J. 2007. Spontaneous in-planta changes in fungal endophytes impact symbiosis. pp $191 \quad$ In: Proceedings of the 6th International Symposium on Fungal Endophytes of Grasses, Eds. Popay, A.J.; Thom, E.R. Grassland Research \& Practice Series 13. New Zealand Grassland Association.

Spiering, M.J.; Lane, G.A.; Christensen, M.J.; Schmid, J. 2005. Distribution of the fungal endophyte Neotyphodium lolii is not a major determinant of the distribution of fungal alkaloids in Lolium perenne plants. Phytochemistry 66: 195-202.

Takemoto, D.; Tanaka, A.; Scott, B. 2006. A p67 ${ }^{\text {Phox }-l i k e ~ r e g u l a t o r ~}$ is recruited to control hyphal branching in a fungal-grass mutualistic symbiosis. The Plant Cell 18: in press.

Tanaka, A.; Christensen, M.J.; Takemoto, D.; Park, P.; Scott, B. 2006. Reactive oxygen species play a role in regulating a fungus-perennial ryegrass mutualistic association. The Plant Cell 18: 1052-1066.

Tanaka, A.; Christensen, M.J.; Takemoto, D.; Scott, B. 2007. Endophyte production of reactive oxygen species is critical for maintaining the mutualistic symbiotic interaction between Epichloëfestucae and Pooid grasses. pp 185 In: Proceedings of the 6th International Symposium on Fungal Endophytes of Grasses, Eds. Popay, A.J.; Thom, E.R. Grassland Research \& Practice Series 13. New Zealand Grassland Association.

Welty, R.E.; Azevedo, M.D. 1993. Endophyte content of seed harvested from endophyte-infected and endophyte-free tall fescue. Journal of Applied Seed Production 11: 6-12.

White J.F Jr, 1988. Endophyte-host associations in forage grasses. XI. A proposal concerning origin and evolution. Mycologia 80 (4): 442-446.

Wilson, S.M.; Easton, H.S. 1997. Seed transmission of an exotic endophyte in tall fescue. pp. 281-283. In: Neotyphodium/ Grass Interactions, Eds. Bacon, C.W.; Hill, N.S., New York: Plenum Press.

Tan, Y.Y.; Spiering, M.J.; Scott, V.; Lane, G.A.; Christensen, M.J.; Schmid, J. 2001. In planta regulation of extension of an endophytic fungus and maintenance of high metabolic rates in its mycelium in the absence of apical extension. Applied and Environmental Microbiology 67: 5377-5383. 